\title{
SOLUBILIDADE DE SAIS DE CARBONATOS EM MISTURAS AQUOSAS CONTENDO MONOETILENOGLICOL NA PRESENÇA DE DIÓXIDO DE CARBONO
}

\author{
N.S.A. MANIÇOBA ${ }^{1}$, D.C. ANDRADE ${ }^{1}$, L.S. PEREIRA ${ }^{2}$, J.F. NASCIMENTO ${ }^{2}$, O. \\ CHIAVONE-FILHO ${ }^{1}$ \\ ${ }^{1}$ Universidade Federal do Rio Grande do Norte, Departamento de Engenharia Química \\ ${ }^{2}$ Petrobras/CENPES/PDEP/TPP \\ E-mail para contato: naira_sinara@hotmail.com
}

\begin{abstract}
RESUMO - Durante o processo de exploração e produção de petróleo e gás, inibidores de formação de hidratos como o monoetilenoglicol (MEG) são adicionados ao sistema, a fim de favorecer a produção e garantir a viabilidade econômica e segurança da operação. Contudo quando em contato com os íons presentes na água de formação, o MEG pode levar a diminuição da solubilidade dos sais, potencializando o processo de precipitação e, consequentemente, incrustações ocasionando bloqueio de linhas e parada da unidade. Este trabalho visa estudar o comportamento de sistemas aquosos contendo MEG e sais de carbonatos de estrôncio $\left(\mathrm{SrCO}_{3}\right)$ e ferro $\left(\mathrm{FeCO}_{3}\right)$, suas características e propriedades, avaliando dados de solubilidade e outros parâmetros termodinâmicos, além de corroborar os dados da literatura sobre o carbonato de cálcio $\left(\mathrm{CaCO}_{3}\right)$ em solução aquosa com os observados. A metodologia utilizada consiste na determinação da solubilidade dos carbonatos em solução aquosa contendo diferentes concentrações de MEG, sob diferentes pressões parciais de $\mathrm{CO}_{2}$ ou na ausência deste composto. $\mathrm{O}$ comportamento identificado a partir da avaliação dos dados de solubilidade mostra que o aumento da concentração de MEG causa uma diminuição da solubilidade dos sais no sistema e o mesmo efeito é observado para o aumento de temperatura. Já a influência aumento da pressão parcial de $\mathrm{CO}_{2}$ se dá no sentido de aumentar a solubilidade dos sais, diminuindo a quantidade de precipitado no sistema. Tais dados são fundamentais para a otimização dos projetos e operação das plantas de regeneração de MEG.
\end{abstract}

\section{INTRODUÇÃO}

Durante o processo de produção de petróleo e gás diversos produtos químicos, tais como inibidores de corrosão, inibidores de formação de hidratos, antiaglomerantes e desemulsificantes são adicionados ao sistema a fim de estimular e favorecer a produção. $\mathrm{O}$ monoetilenoglicol (MEG) é o principal solvente utilizado como inibidor da formação de hidratos de gás, os quais caracterizam sólidos cristalinos desenvolvidos em condições de baixa temperatura e altas pressões e podem vir a ocasionar bloqueios de dutos e outros problemas operacionais na indústria do petróleo e gás, já que possui propriedades importantes 
no que diz respeito a redução do ponto de congelamento dos fluidos produzidos nos dutos por meio da mudança do potencial químico da água na ação contra corrosão.

Com a produção de petróleo e gás produz-se também água. A água produzida é salina, e produtos químicos, tais como o MEG, quando em contato com os íons presentes na água de formação, podem levar a diminuição da solubilidade dos sais, influenciando no processo de precipitação.

Este trabalho tem como objetivo estudar o comportamento de sistemas aquosos contendo MEG e sais de carbonatos, principalmente carbonato de estrôncio $\left(\mathrm{SrCO}_{3}\right)$ e carbonato de ferro $\left(\mathrm{FeCO}_{3}\right)$ presentes na água de produção, suas características e propriedades, avaliando dados de solubilidade e outros parâmetros termodinâmicos. Os resultados têm por finalidade obter dados experimentais que auxiliem na otimização do projeto e operação das unidades de regeneração e recuperação de MEG. Dessa forma, as informações experimentais obtidas permitem o entendimento dos processos envolvidos nos equipamentos gerando uma base de dados para o desenvolvimento de modelo termodinâmico que pode ser aplicado para a simulação dos processos envolvidos na regeneração do MEG.

\section{METODOLOGIA}

O método experimental baseia-se na determinação da solubilidade do carbonato de estrôncio e de ferro em solução aquosa contendo diferentes concentrações de MEG, variando a sua porcentagem mássica de 0 a $100 \%$, na presença de dióxido de carbono com pressões parciais de 760 a 1610 mmHg, ou na ausência deste composto, à temperatura constante.

Para realização dos experimentos, um aparato foi projetado com duas células de vidro encamisadas, acopladas a um banho termostático e a um sistema de pressurização com buffer, conectado a um cilindro de $\mathrm{CO}_{2}$, com ajuda de um sistema de válvulas, ou manifold, conforme demonstrado na Figura 1. As amostras são mantidas sob agitação nas mesmas condições de pressão e temperatura por 2 horas e, em seguida, em repouso por um determinado tempo de forma que o máximo de sólido precipite. Após esta etapa, as amostras são coletadas, diluídas e analisadas via absorção atômica.

No que diz respeito ao procedimento experimental utilizado para o carbonato de cálcio, foi aplicada a metodologia semelhante a citada anteriormente. No entanto, foi utilizado um biorreator com volume de $3 \mathrm{~L}$. Os parâmetros monitorados foram o $\mathrm{pH}$, temperatura e concentração de $\mathrm{CaCO}_{3}$.

Apenas nos experimentos realizados com o carbonato de ferro, realiza-se uma etapa adicional que é caracterizada pela síntese deste composto imediatamente antes da realização dos testes de solubilidade. A síntese é realizada em um sistema cuja característica principal é a garantia de ausência de oxigênio para que o composto em questão não oxide. 
Figura 1 - Esquema do aparato experimental utilizado para determinação de solubilidade de sais de carbonato em soluções aquosas de MEG.

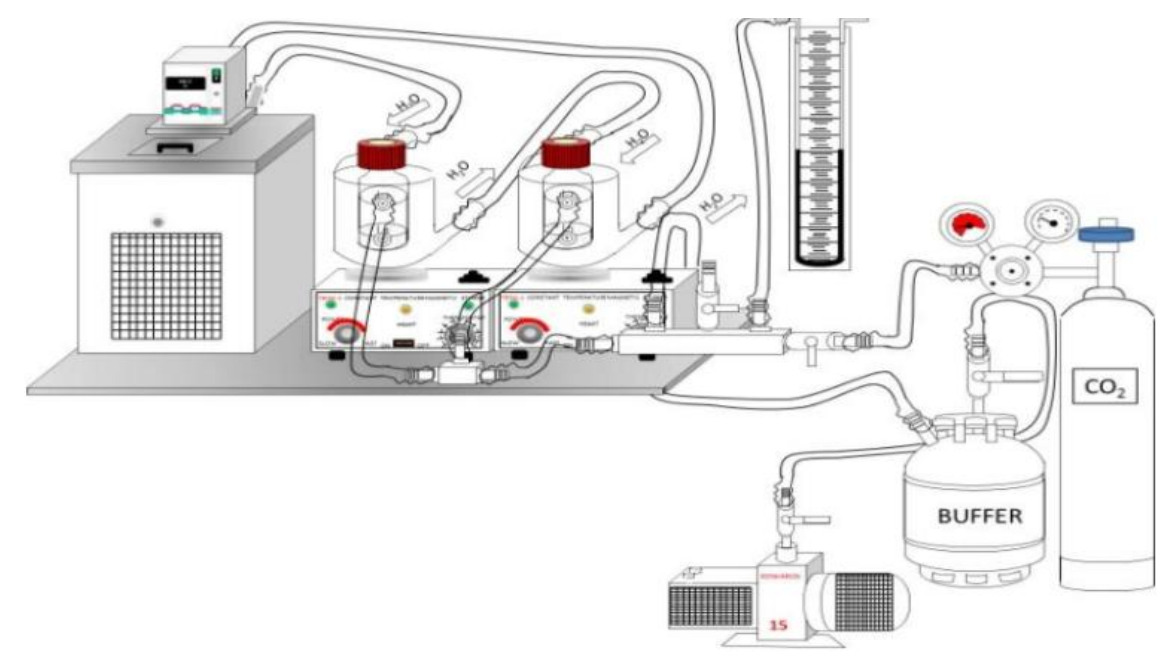

\section{RESULTADOS E DISCUSSÃO}

\subsection{Carbonato de estrôncio $\left(\mathrm{SrCO}_{3}\right)$}

Os experimentos realizados com o carbonato de estrôncio $\left(\mathrm{SrCO}_{3}\right)$, em solução aquosa, apresentaram o comportamento mostrado na Figura 2.

Figura 2 - Dados de solubilidade do $\mathrm{SrCO}_{3}$ em misturas aquosas contendo MEG na presença de dióxido de carbono a $25^{\circ} \mathrm{C}$.

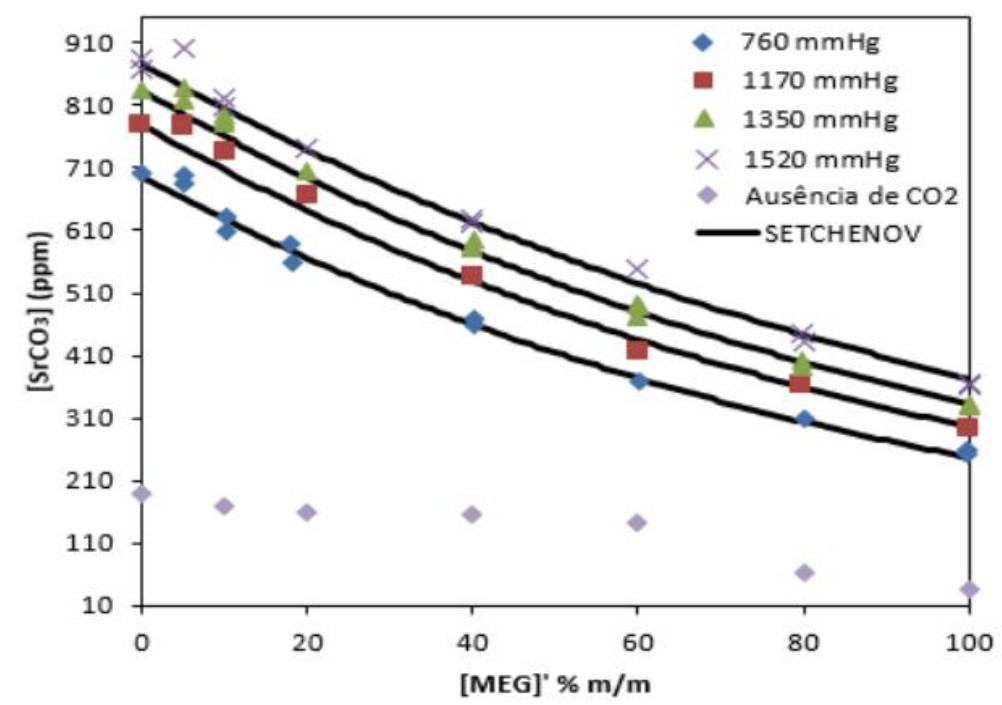

De acordo com os dados da figura 2, nota-se que o aumento da pressão parcial de $\mathrm{CO}_{2}$ ocasiona um aumento da solubilidade do carbonato de estrôncio. Com a adição de monoetilenoglicol (MEG) ao sistema, observa-se o efeito denominado salting-out que pode ser descrito pela diminuição da concentração do sal em solução, ou seja, diminuição da 
solubilidade do sal à medida que é adicionado MEG. Este fato pode representar precipitação de cristais. Por outro lado, aumento da pressão parcial do sistema provoca um aumento na solubilidade do sal em questão e, consequentemente, inibição da precipitação.

É possível perceber ainda que os pontos encontrados experimentalmente encontram-se em concordância com os valores previstos a partir da equação empírica de Setchenov utilizada. Esta equação relaciona as concentrações do sal em estudo na presença do inibidor, a concentração do sal somente em água, as concentrações de MEG livre de sal e a constante de Setchenov.

Além disso, a Figura 2 ilustra o comportamento do sistema contendo carbonato de estrôncio, MEG e água na ausência de dióxido de carbono. Nota-se, dessa forma, a significativa influência que o $\mathrm{CO}_{2}$ possui no sistema estudado. $\mathrm{O}$ efeito do aumento da concentração de MEG no sistema também ocasiona uma diminuição da solubilidade do carbonato de estrôncio, porém em proporções bem maiores do que as evidenciadas quando o $\mathrm{CO}_{2}$ não está ausente.

\subsection{Carbonato de ferro $\left(\mathrm{FeCO}_{3}\right)$}

No caso do carbonato de ferro a mesma análise de concentração do sal em relação a concentração de MEG na amostra é realizada. No entanto, o valor real da concentração de MEG presente nas amostras é determinado a partir do parâmetro densidade. Para isso, constrói-se uma curva de calibração a partir da densidade medida e concentração de MEG livre de sal adicionado de acordo com a Figura 3.

Figura 3 - Concentração de MEG versus densidade medida.

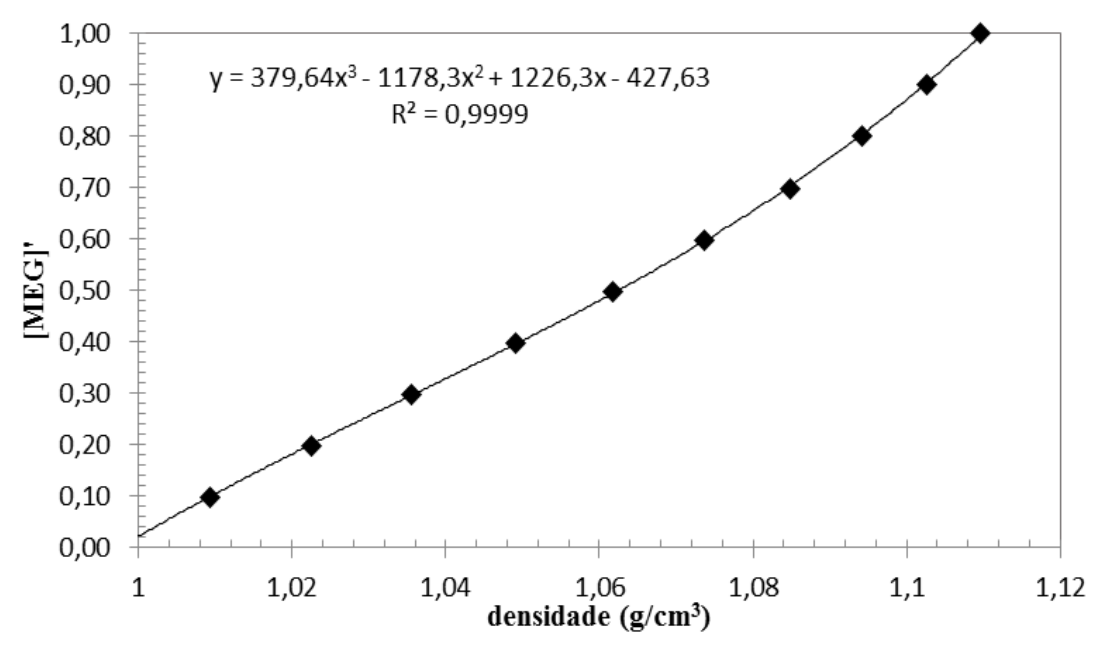

A partir da equação fornecida pela Figura 3 é possível, então, encontrar os valores reais de MEG presentes na amostra. Dessa forma, pode-se construir o gráfico que relaciona a concentração de carbonato de ferro presente na alíquota em questão e a quantidade de MEG. Este perfil pode ser visualizado na Figura 5. 
Figura 4 - Dados de solubilidade do $\mathrm{FeCO}_{3}$ em misturas aquosas contendo MEG na presença de dióxido de carbono a $25^{\circ} \mathrm{C}$.

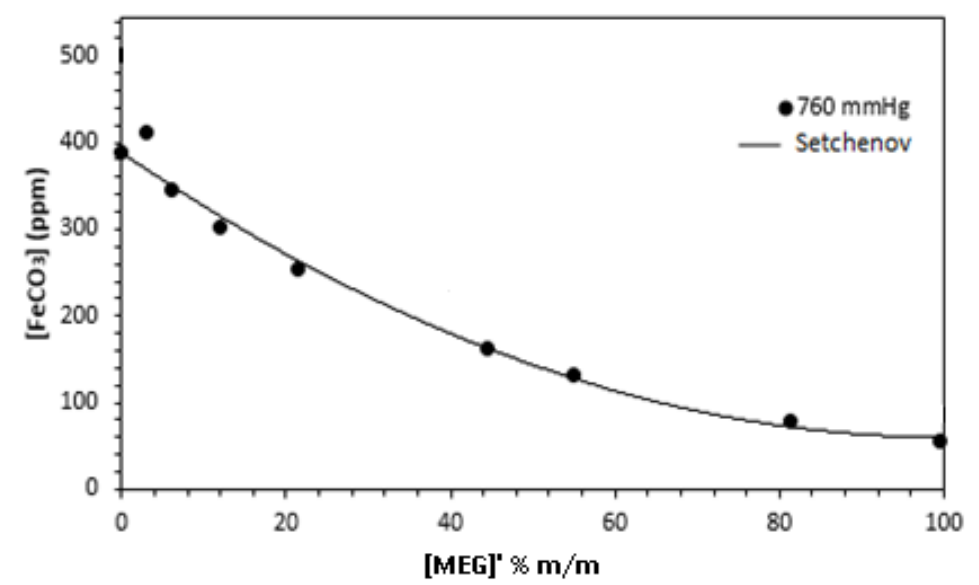

Semelhante ao comportamento do carbonato de estrôncio, o comportamento do carbonato de ferro em sistema contendo água e MEG apresenta a característica de redução na quantidade de sais solubilizados com o aumento da composição de MEG presente para uma pressão de $760 \mathrm{mmHg}$. Dessa forma, o efeito salting-out também pode ser verificado neste sistema.

\subsection{Experimentos preliminares com carbonato de cálcio $\left(\mathrm{CaCO}_{3}\right)$}

Em relação ao carbonato de cálcio $\left(\mathrm{CaCO}_{3}\right)$, análise de solubilidade foi realizada em torno dos parâmetros temperatura e $\mathrm{pH}$, como medida indireta da quantidade de $\mathrm{CO}_{2}$ envolvida no sistema. O comportamento deste carbonato em função da temperatura encontrase na Figura 5.

Figura 5 - Dados de solubilidade do $\mathrm{CaCO}_{3}$ em misturas aquosas na presença de dióxido de carbono em diferentes temperaturas.

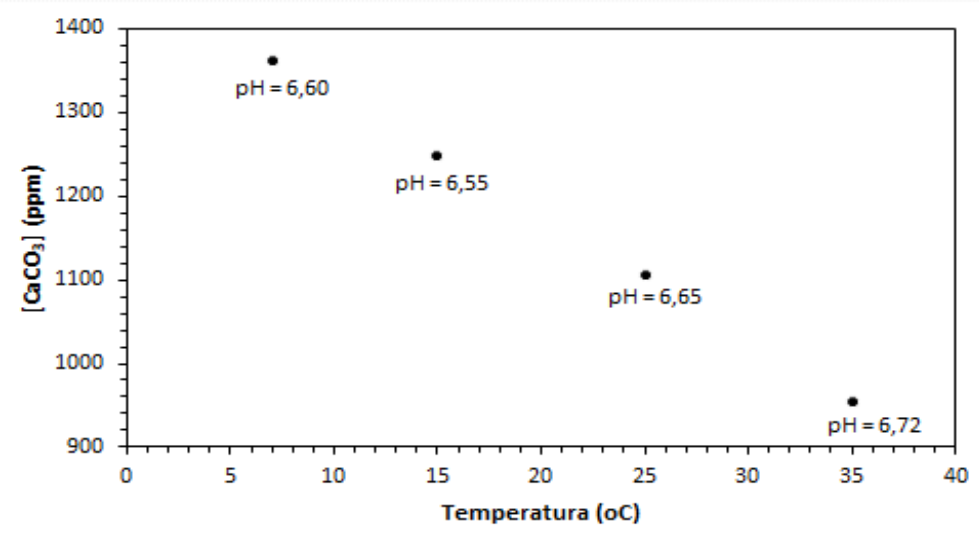

A Figura 5 ilustra a influência da temperatura na solubilidade do carbonato de cálcio em solução aquosa. É possível notar que a medida que o sistema é submetido a maiores temperaturas a solubilidade do sal tende a diminuir, ou seja, ocorre uma maior deposição de 
cristais precipitados, confirmando o comportamento esperado. Contudo, os valores observados estão acima da saturação considerando os valores da literatura (Plummer e Busenberg, 1982), indicando que o procedimento experimental ainda requer ajustes.

Outro parâmetro relevante trata-se do efeito do $\mathrm{pH}$, o qual está intimamente relacionado com a pressão parcial de $\mathrm{CO}_{2}$ e com o equilíbrio químico das espécies. Logo, ele pode modificar a distribuição de diferentes espécies iônicas presentes na solução, afetando a deposição ou a solubilização do carbonato de cálcio. Quanto maior a pressão parcial de $\mathrm{CO}_{2}$, maior a quantidade de dióxido de carbono dissolvido e menor será o $\mathrm{pH}$ evidenciado. Dessa forma, isto implicará no deslocamento do equilíbrio no sentido da precipitação do carbonato de cálcio, conforme observado na Figura 5

\section{CONCLUSÃO}

Inúmeros são os benefícios que estão associados ao estudo da recuperação do monoetilenoglicol, sobretudo a importância deste no que diz respeito à demanda da indústria do petróleo e gás. Como exemplos, citam-se a redução de custos com o reaproveitamento do produto recuperado e o controle de resíduos que se acumulam nas tubulações e que podem prejudicar o meio ambiente. Juntamente com a importância industrial, o projeto de pesquisa tem permitido a formação de recursos humanos orientado para o setor.

Os dados experimentais coletados contribuem para identificar o comportamento de sistema aquosos contendo MEG e sais de carbonatos, nas condições de interesse da plataforma, a fim de avaliar como a concentração das espécies alteram o comportamento de fases, provocando, por exemplo, a diminuição da solubilidade dos cristais e, assim, aumentando a incidência de incrustação nos equipamentos. Tais dados são fundamentais para auxiliar nos estudos de otimização dos projetos e operação das unidades de regeneração de MEG.

\section{REFERENCIAS}

CARVAlHO, C. M. de S. F.; Cinética de crescimento de siderita (FeCO3) e dissolução de halita $(\mathrm{NaCl})$ em soluções de água e MEG. Tese de doutorado. Rio de janeiro, 2016.

CHIAVONE-FILHO, O., P. Rasmussen, Modeling Salt Solubilities in Mixed Solvents, Brazilian Journal of Chemical Engineering, vol. 17(2), p. 130-158 (2000).

CHIAVONE-FILHO, O., Rasmussen, P. Solubilities of salts in mixed solvents. Journal of Chemical Engineering Data, vol. 38, p. 367-369 (1993).

PLUMMER, L. N., BUSENBERG, E.; The solubilities of calcite, aragonite and vaterite in $\mathrm{CO} 2-\mathrm{H} 2 \mathrm{O}$ solutions between 0 and $90^{\circ} \mathrm{C}$, and an evaluation of the aqueous model for the system CaCO3-CO2-H2O.Geochimica et Cosmochimica Acta, Vol. 46, p. 1011-1040, 1982.

SOBRINHO, Patricia Alves. Estudos Termodinâmicos do Processo de Regeneração de Monoetilenoglicol (MEG). Monografia de graduação. Natal, 2013. 